\title{
PERFIL EPIDEMIOLÓGICO DOS ATENDIMENTOS ANTIRRÁBICOS HUMANOS NO MUNICÍPIO DE CHAPECÓ, SC
}

\author{
EPIDEMIOLOGICAL PROFILE OF HUMAN ANTI-RABIES CARE IN THE MUNICIPALITY
}

OF CHAPECÓ, SC

\author{
Fabíola Inês Salvi ${ }^{1}$ \\ Jéssica Moreira de Paula ${ }^{2}$ \\ Junir Antonio Lutinski ${ }^{3}$ \\ Douglas Michel Muller Fritzen ${ }^{4}$ \\ Karina Giachini ${ }^{5}$ \\ Francis Maira Schabat ${ }^{6}$ \\ Maria Assunta Busato ${ }^{7}$ \\ Recebido em: 10 abr. 2018 \\ Aceito em: 12 jun. 2018
}

RESUMO: A raiva se destaca dentre as zoonoses pela sua letalidade. Pesquisas sobre a dispersão, transmissão viral e hospedeiros têm ajudado as autoridades de saúde na adoção de medidas de controle. Neste contexto, este estudo teve como objetivo descrever o perfil das pessoas que tiveram atendimento antirrábico no município do Chapecó, SC. Foram avaliados os acidentes registrados no período de 2012 a 2016, fornecidos pela Vigilância Epidemiológica de Chapecó, SC. Foram avaliadas variáveis relativas às faixas etárias, ocupação e sexo. Ao todo, 2430 notificações foram avaliadas. As faixas etárias mais acometidas foram de crianças entre 1 e 14 anos e de adultos em idade economicamente ativa, 20 a 59 anos. Os atendimentos foram mais frequentes em estudantes $(16,5 \%)$ e aposentados ou pensionistas $(9,3 \%)$. O sexo masculino foi o mais acometido nos anos de 2012, 2013 e 2014, enquanto em 2015 e 2016 foi o sexo feminino. Considerando o papel dos cães como reservatórios do vírus da raiva, emerge a necessidade de ações voltadas para o bem-estar animal e para a prevenção de acidentes. A frequência dos atendimentos envolvendo crianças indica a vulnerabilidade desta faixa etária enquanto acidentes envolvendo adultos implica em perdas econômicas associadas aos dias parados de trabalho.

Palavras-chave: Acidentes. Promoção da saúde. Zoonoses.

ABSTRACT: Rabies stands out among zoonoses for their lethality. Research on dispersal, viral transmission and hosts have helped health authorities in adopting control measures. In this context, this study aimed to describe the profile of people who

\footnotetext{
1 Programa de Pós-Graduação em Ciências da Saúde, Universidade Comunitária da Região de Chapecó (Unochapecó), Chapecó, SC, Brasil. fabiola.salvi@unochapeco.edu.br.

2 Vigilância em Saúde Ambiental do município de Chapecó, SC, Brasil. E-mail: jessica.paula@unochapeco.edu.br.

3 Programa de Pós-Graduação em Ciências da Saúde, Universidade Comunitária da Região de Chapecó (Unochapecó), Chapecó, SC, Brasil. E-mail: junir@unochapeco.edu.br.

4 Vigilância em Saúde Ambiental do município de Chapecó, SC, Brasil. E-mail: dmmfritzen@gmail.com.

5 Vigilância em Saúde Epidemiológica da Secretaria de Saúde de Chapecó, SC. E-mail: giachinikarina@unochapeco.edu.br.

6 Vigilância em Saúde Ambiental do município de Chapecó, SC, Brasil. E-mail: franschabat@hotmail.com.

7 Programa de Pós-Graduação em Ciências da Saúde, Universidade Comunitária da Região de Chapecó (Unochapecó), Chapecó, SC, Brasil. E-mail: assunta@unochapeco.edu.br.
} 
had anti-rabaric care in the municipality of Chapecó, SC. We evaluated the accidents recorded in the period from 2012 to 2016, provided by the Epidemiological Surveillance of Chapecó, SC. Variables related to age groups, occupation and sex were evaluated. In all, 2,430 notifications were evaluated. The most affected age groups were children between 1 and 14 years old and adults in economically active age, 20 to 59 years. The attendances were more frequent in students (16.5\%) and retirees or pensioners (9.3\%). Males were the most affected in the years of 2012, 2013 and 2014, while in 2015 and 2016, changes to females. Considering the role of dogs as reservoirs of the rabies virus, it's necessary actions aimed at animal welfare and the prevention of accidents. The frequency of attendances involving children indicates the vulnerability of this age group while accidents involving adults imply economic losses associated with the unemployed days.

Keywords: Accidents. Health promotion. Zoonoses.

\section{INTRODUÇÃO}

Os acidentes por mordeduras de cães são objeto de preocupação devido ao seu potencial para transmissão de zoonoses, como a raiva, infecções, sequelas físicas e psicológicas (PARANHOS et al., 2013). Estes acidentes ocorrem numa frequência elevada no Brasil, sendo um importante agravo à saúde (DEL CIAMPO et al., 2000; BUSO; NUNES e QUEIROS, 2009; PARANHOS et al., 2013). Os custos monetários e sociais necessários para o tratamento desses acidentes demandam recursos que poderiam ser investidos em outros programas de promoção à saúde (DEL CIAMPO et al., 2000; PARANHOS et al., 2013).

Estas intercorrências estão associadas a situações em que o animal demostra dominância, defesa territorial, competição por alimento, proteção de membros jovens da matilha ou de outros indivíduos. Também podem acontecer por dor, medo e instinto predatório interespecífico (PARANHOS et al., 2013). Machos apresentam maior inclinação para agressividade, devido a fatores hormonais, fato também atribuído a animais mais jovens (BUSO; NUNES e QUEIROS, 2009). Em geral os ataques ocorrem em situações onde há alterações posturais por parte dos seres humanos. Contato visual e carícias também podem ser provocativas para alguns cães (PARANHOS et al., 2013).

A raiva é uma antopozoonose que causa danos neurológicos permanentes em seu portador. A principal via de inoculação do vírus se dá através de mordeduras, arranhaduras e lambeduras de animais infectados. Existem três ciclos da doença: o urbano, onde cães e gatos são os principais transmissores, o rural, através de bovinos, equídeos, caprinos e ovinos e, o ciclo silvestre, onde a inoculação ocorre pela mordida de morcegos hematófagos (FRIAS; LAGES e CARVALHO, 2011).

Esta antropozoonose se caracteriza como uma encefalite progressiva e aguda com $100 \%$ de letalidade em humanos contaminados. Configura-se como um problema de saúde pública mundial, onerando custos em campanhas de vigilância, controle e prevenção, além de atendimento aos doentes. Ainda endêmica em todo mundo, está predominantemente associada a regiões com menor índice de desenvolvimento (LOPES et al., 2014; 
MOUTINHO; NASCIMENTO e PAIXÃO, 2015).

No Brasil, no período de 2010 a 2016 foram confirmados 17 casos de raiva humana, nenhum sendo em Santa Catarina. No ciclo urbano, a principal forma da inoculação do vírus é através de mordeduras de cães. Em Santa Catarina, período de 2010 a 2016 foram notificados mais de 100 mil acidentes por mordedura com potencial antirrábico, sendo destes 2.430 em Chapecó (BRASIL, 2016).

Os acidentes por mordeduras de cães são relativamente comuns, em muitos casos não chegando as autoridades sanitárias. Além da raiva, as mordidas caninas podem trazer diversas complicações à saúde humana. Como possuem dentes rombos e mandíbulas robustas, podem causar esmagamento e lacerações de tecidos, músculos, vasos, tendões e ossos (HADDAD JUNIOR; CAMPOS NETO e MENDES, 2013). Acompanhando as lesões estruturais imediatas, ocorre a inoculação de bactérias, fungos e demais patógenos que normalmente se encontram alojados na cavidade oral canina, podendo causar infecções. As infecções são de natureza mista, envolvendo várias espécies de bactérias, incluindo o Clostridium tetani Nicolaier e Kitasato, 1886 e outras espécies que podem levar o paciente a quadros como meningite, pneumonia, insuficiência renal, sepse e outras (BUSO; NUNES e QUEIROZ, 2009; HADDAD JUNIOR; CAMPOS NETO e MENDES, 2013).

Atualmente, na literatura disponível, há escassos registros acerca do perfil das pessoas envolvidas nos acidentes com mordedura de cães, se atendo ao atendimento pósexposição. Ferraz et al. (2013) descreveram o perfil dos atendimentos antirrábicos notificados no município de Chapecó relativo aos anos de 2009 e 2010, contudo, nenhum outro estudo desta natureza foi realizado posteriormente. A caracterização do perfil dos acidentes e o perfil epidemiológico pode oferecer subsídios às autoridades sanitárias para a implementação de ações de prevenção da raiva e de outras zoonoses. Neste contexto, este estudo teve como objetivo descrever o perfil epidemiológico dos atendimentos antirrábicos humanos no município do Chapecó, SC.

\section{MATERIAL E MÉTODOS}

O estudo se caracteriza como transversal, descritivo, de caráter quantitativo, com base em informações do banco de dados da Secretaria de Saúde de Chapecó. Este

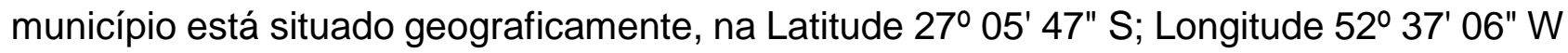
e Altitude $674 \mathrm{~m}$. Possui uma área total de $625.758 \mathrm{~km}^{2}$ e localiza-se aproximadamente a 600 quilômetros da capital Florianópolis. Destaca-se das demais cidades da região por ser considerado um polo econômico regional e por se encontrar na rota do comércio e do turismo da região Sul do Brasil. Conta com uma população de 209.553 (IBGE, 2017).

A coleta de dados se deu com base nas fichas de investigação de atendimento antirrábico humano registradas no Sistema de Informação de Agravos de Notificação (SINAN), pelo setor de Vigilância Epidemiológica do município, relativos ao período de 2012 a 2016. 
As variáveis utilizadas foram o sexo, idade, escolaridade, zona de moradia e ocupação. Os dados obtidos foram organizados, tabulados e avaliados quanto à frequência com auxílio do software Excel for Windows (MICROSOFT, 2015)

O estudo foi realizado com dados secundários, apresentados de forma coletiva e não foram acessadas informações nominais ou que pudessem identificar os indivíduos. A utilização do banco de dados foi autorizada pela Secretaria de Saúde do município.

\section{RESULTADOS}

No período avaliado foram registrados 2.430 atendimentos antirrábicos, nenhum evoluiu para diagnóstico de raiva. As faixas etárias mais acometidas foram crianças de 5 a 9 anos, com 310 notificações, média de 62 atendimentos/ano (12,75\%), seguida dos adultos de 30 a 39 anos, com 274 notificações média de 54,4 atendimentos/ano (11,27\%), a faixa de 20 a 29 anos, com 257 acidentes, média de 51,4 atendimentos/ano (10,57\%) e a faixa dos 40 a 49 anos, com 248 acidentes, média de 49,6 atendimentos/ano (10,20\%). Cabe destacar o registro de $261(10,7 \%)$ atendimentos envolvendo pessoas idosas (60 anos ou mais) (Figura 1).

Figura 1 - Média anual de atendimento antirrábico no município de Chapecó, segundo a faixa etária, 2012 a 2016. As barras verticais indicam o erro padrão da média.

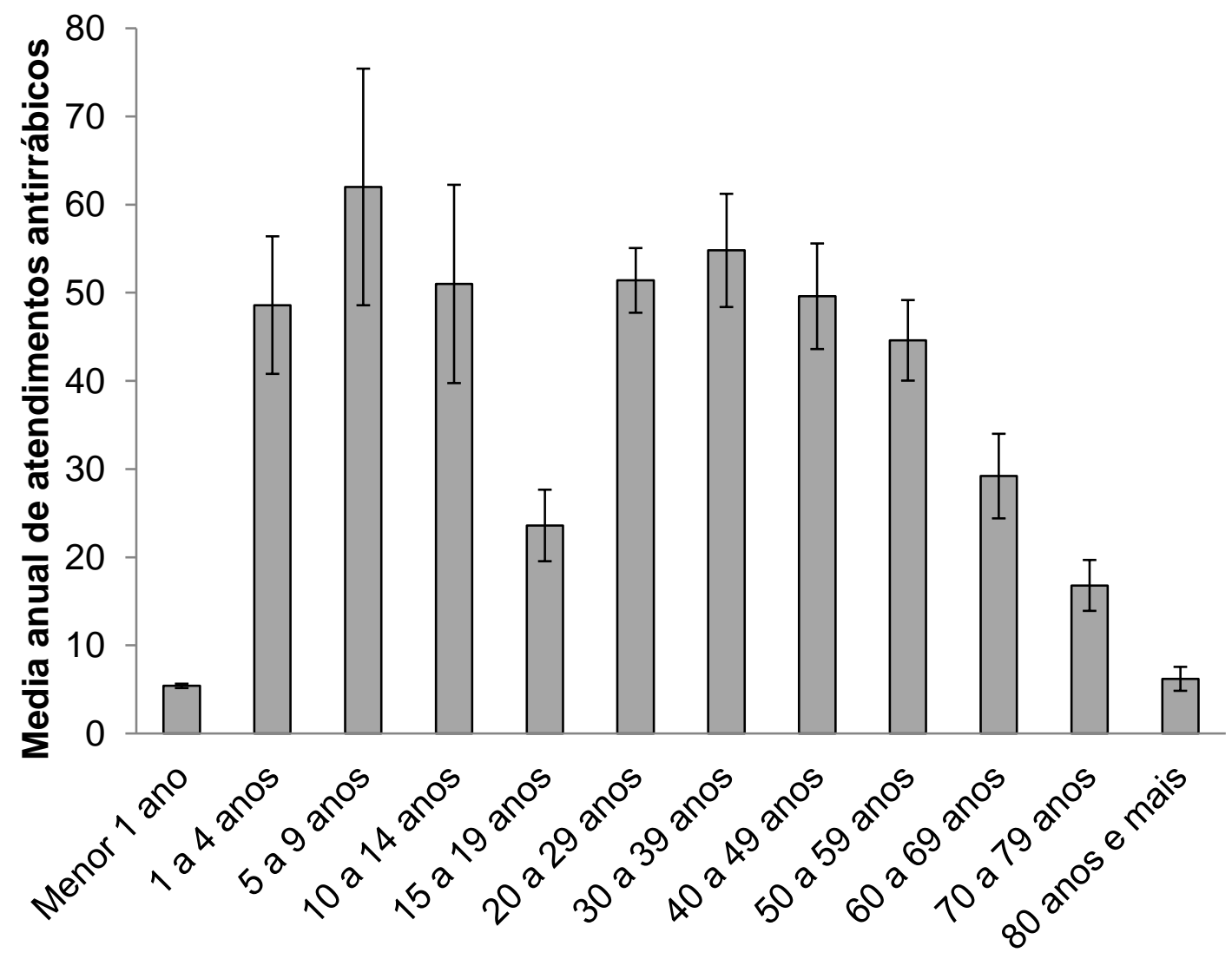

Faixa etária

As notificações, segundo o sexo, não mostraram grandes variações sendo 244,6 
notificações/ano para homens e 241,4 para mulheres. Os números, ano a ano, mostraram predominância dos acidentes em homens nos anos de 2012, 2013 e 2014, seguidos de uma inversão nos anos de 2015 e 2016 período em que as notificações em mulheres foram maiores (Figura 2).

Figura 2 - Médias anuais de atendimento antirrábico no município de Chapecó, segundo o sexo, 2012 a 2016.

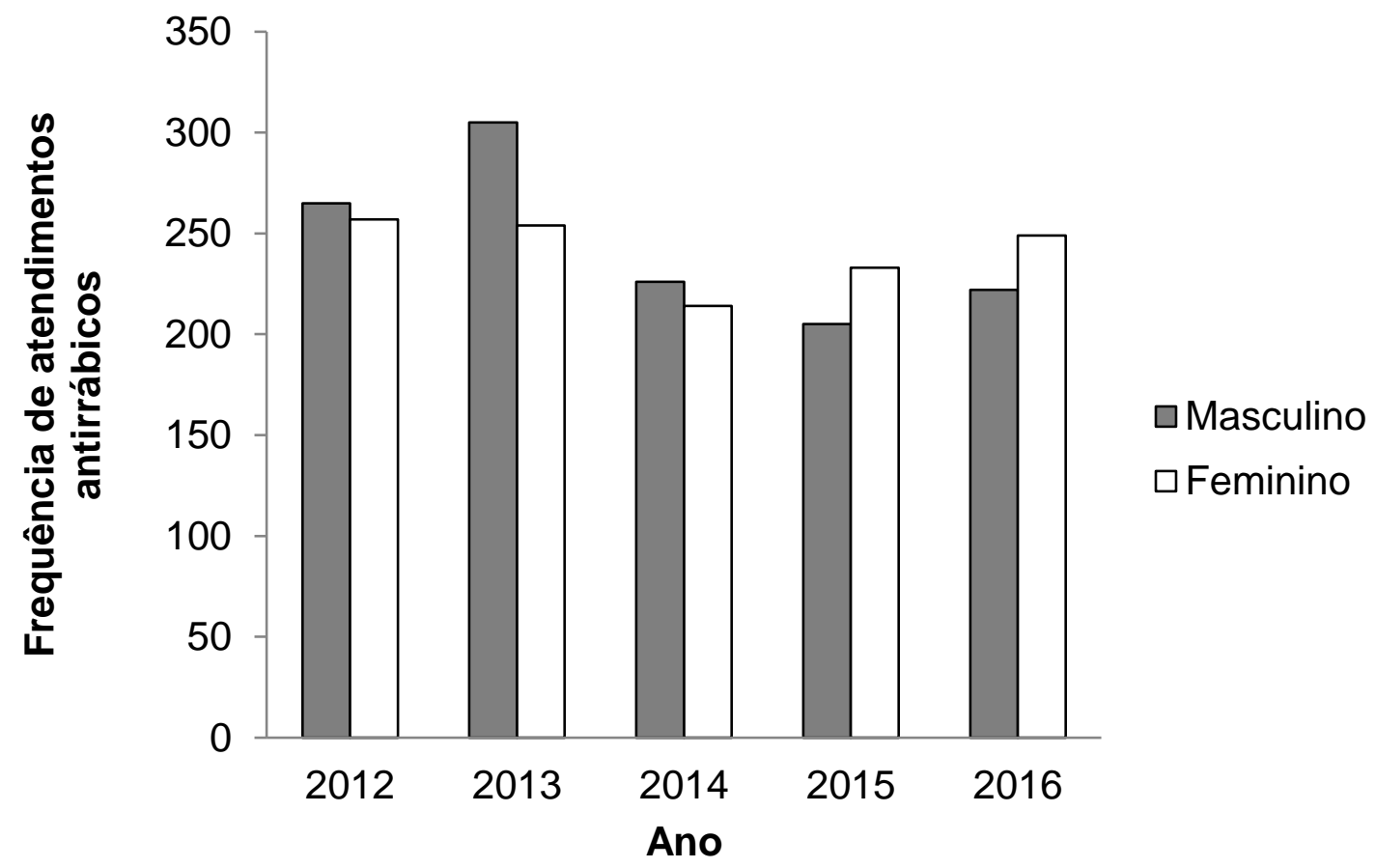

Em 2013 houve o maior registro de notificações com 559 atendimentos, seguido de 2012 com 522 acidentes (Figura 2). A média dos atendimentos mostrou-se maior no mês de janeiro com média de 55,6 atendimentos, seguido pelos meses de setembro com 46,2 e agosto com 44 atendimentos/mês (Figura 3 ). 
Figura 3 - Frequência média mensal dos atendimentos antirrábicos no município de Chapecó, 2012 a 2016. As barras verticais indicam o erro padrão da média.

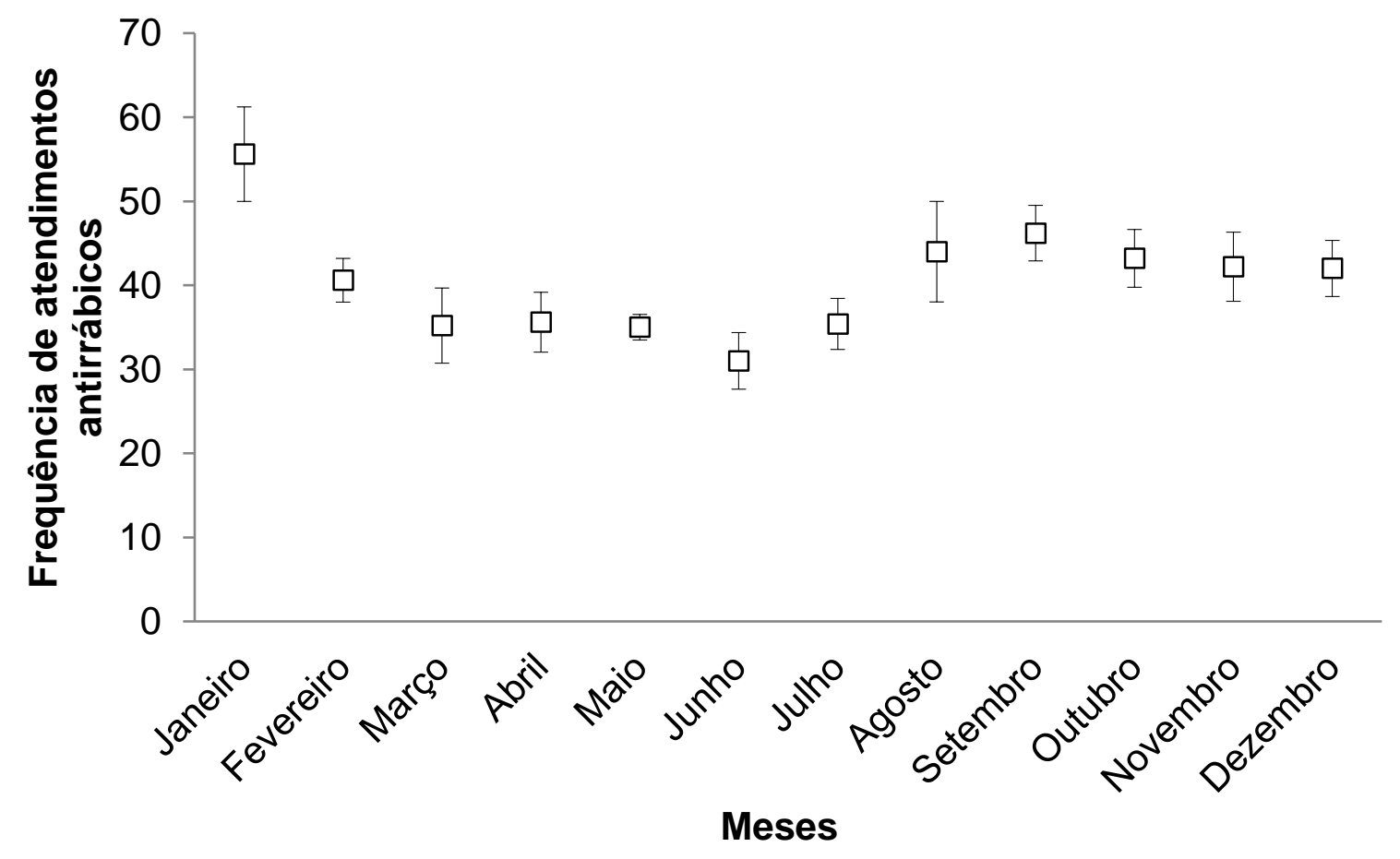

Quanto à zona de residência a maioria dos acidentes (91,9\%) ocorreu na área urbana seguido de $6 \%$ na área rural. Quanto à ocupação das pessoas envolvidas nos atendimentos antirrábicos observou-se que os estudantes foram os mais afetados sendo registrados 402 acidentes $(16,5 \%$,) seguido dos apesentados/pensionistas com 225 atendimentos $(9,3 \%)$, donas de casa com 171 atendimentos $(7 \%)$ e desempregados com 119 atendimentos $(4,9 \%)$. Destaca-se a categoria "Não identificado", ou seja, falta de preenchimento do campo "Ocupação" no formulário, com o maior percentual (884 atendimentos $(34,7 \%)$ seguido da categoria "Outros" com 447 atendimentos $(18,4 \%)$ (Tabela 1). 
Tabela 1 - Percentual de notificações de atendimentos antirrábicos no município de Chapecó, segundo a ocupação, 2012 a 2016.

\begin{tabular}{lll}
\hline Ocupação & Total & Percentual (\%) \\
\hline Não identificado & 844 & 34,7 \\
Outros & 447 & 18,4 \\
Estudante & 402 & 16,5 \\
Aposentado/pensionista & 225 & 9,3 \\
Dona de casa & 171 & 7,0 \\
Desempregado & 119 & 4,9 \\
Apontador de produção & 32 & 1,3 \\
Trabalhador volante da agricultura & 24 & 1,0 \\
Vendedor de comércio varejista & 21 & 0,9 \\
Pedreiro & 21 & 0,9 \\
Apontador de mão-de-obra & 16 & 0,7 \\
Servente de obras & 16 & 0,7 \\
Motorista de caminhões & 16 & 0,7 \\
Faxineiro & 12 & 0,5 \\
Gerente administrativo & 11 & 0,5 \\
Auxiliar de escritório & 11 & 0,5 \\
Cozinheiro geral & 11 & 0,5 \\
Vigilante & 11 & 0,5 \\
Mecânico & 10 & 0,4 \\
Professor & 10 & 0,4 \\
\hline Total & $\mathbf{2 4 3 0}$ & \\
\hline
\end{tabular}

\section{DISCUSSÃO}

Os acidentes com potencial antirrábico acometem todas as faixas etárias, contudo, observou-se que as crianças entre 5 e 9 anos foram as mais nesses acidentes, fato esse observado também por Buso, Nunes e Queiroz (2009), Oliveira et al. (2012), Paranhos et al. (2013), Gomes et al. (2014), Silva e Costa (2016) e Lima et al. (2017). Alguns autores relacionam a maior incidência de ataques nesta faixa etária devido às crianças estarem mais expostas e terem comportamento de risco ao se aproximando de animais durante a alimentação, animais acuados ou em situação de risco (BUSATO et al., 2014; LOPES et al., 2014) e que a maioria dos acidentes com crianças na faixa etária de 5 a 9 anos ocorre durante brincadeiras com os animais agressores (PARANHOS et al., 2013). Busato et al. (2014) chamam a atenção para o fato de crianças e adolescente de até 15 anos serem mais susceptíveis a ataques de caninos por frequentarem com mais assiduidade quintais de suas casas, parques e ruas como áreas de lazer. Quanto às notificações envolvendo as faixas etárias entre 20 ate os 59 anos, idade economicamente ativa, estudos citam o deslocamento em vias públicas como principal fator de risco para os ataques (VELOSO et al., 2011; OLIVEIRA et al., 2012; CAVALCANTE, FLORENCIO e ALENCAR, 2017). Ainda, 
Veloso et al. (2011) apontam que adultos teriam maior suscetibilidade aos ataques devido a atividades laborais em que estão inseridos os cuidadores de animais e carteiros.

Embora a média de atendimentos antirrábicos tenha variado pouco entre os sexos, houve predominância dos acidentes em indivíduos do sexo masculino, o que corrobora com outros estudos relacionados ao perfil epidemiológicos de atendimentos antirrábicos no Brasil (VELOSO et al., 2011; QUEIROZ; BUSO e SILVA, 2013; SILVA et al., 2013; SILVA e COSTA, 2016; CAVALCANTE; FLORÊNCIO e ALENCAR, 2017).

A maior frequência de notificações no mês de janeiro (55,6 atendimentos/mês) pode estar relacionada ao período de férias escolares e férias da população em geral. No período de férias aumenta a circulação de indivíduos em vias públicas. Este resultado corrobora os achados de Ferraz et al. (2013), Oliveira et al. (2012) e Lopes et al. (2014) e representa uma informação relevante para as ações de prevenção a esse tipo de acidente.

A maioria das notificações tiveram como envolvidos, indivíduos residentes na área urbana. Resultados semelhantes foram obtidos nos estudos de Queiroz, Buso e Silva (2013), Silva et al. (2013), Lopes et al. (2014), Silva e Belo (2015) e Silva e Costa (2016). Moutinho, Nascimento e Paixão (2015) ao analisarem as ações de vigilância e controle da raiva no estado do Rio de Janeiro destacam a importância do censo ou outro método que dimensione a população destes animais em áreas urbanas, possibilitando fixar metas de prevenção de acidentes e de controle de zoonoses. A presença de cães errantes, comunitário ou com acesso livre a vias públicas é um dos fatores de risco para o aumento do número de casos de acidentes (PEREIRA; BOSCHETI e PEREIRA, 2016; MOUTINHO; NASCIMENTO e PAIXÃO, 2015). Não há dados oficiais em relação à população de animais em situação de abandono no município de Chapecó.

Quanto à ocupação, estudantes foram os mais relacionados nos atendimentos antirrábicos, corroborando os resultados de Oliveira et al. (2012). Nas classes aposentados e donas de casa os acidentes podem estar associados aos fatores de exposição, pois estes indivíduos passam mais tempo com seus animais de estimação (LOPES et al., 2014). Quanto à classe "desempregado", os acidentes podem acontecer devido à exposição dos indivíduos às vias publicas, onde há maior concentração de animais errantes (OLIVEIRA et al., 2012). Ainda, é oportuno destacar o percentual atingido pela categoria "Não Informado" que evidencia fragilidade nas notificações. Estudos prévios destacam a importância da redução de falhas no preenchimento do formulário, pois esse documento fornece informações quantitativas e qualitativas do atendimento Essas fragilidades evidenciam a importância de capacitação permanente das equipes de saúde para um correto preenchimento da ficha de notificação de atendimento antirrábico humano (SANTOS; MELO e BRANDESPIM, 2017). Dentro das possibilidades das esquipes de saúde, seria oportuno uma visita zoossanitária para identificação das causas de agressão por animais pois, segundo Frias, Carvalho e Nunes (2016), as pessoas têm dificuldade em entender o comportamento animal.

De posse de informações detalhadas é possível avaliar a qualidade do atendimento, além de proporcionar informações epidemiológicas para a formulação de 
campanhas de promoção da saúde e prevenção de agravos (FRIAS; LAGES e CARVALHO, 2011; OLIVEIRA et al., 2012; FERRAZ et al., 2013; SILVA et al., 2013; SILVA e COSTA, 2016).

\section{CONCLUSÃO}

O perfil dos atendimentos antirrábicos humanos em Chapecó-SC indica que a maior frequência dos acidentes ocorre envolvendo crianças e adultos economicamente ativos. Esse cenário indica a vulnerabilidade a que as crianças estão expostas e as perdas econômicas já que pode refletir em dias perdidos de trabalho.

A ausência de alguns dados na ficha de notificação dificulta a identificação epidemiológica e sociodemográfica dos sujeitos envolvidos o que poderia contribuir para melhor conhecer a população afetada e a proposição de ações de prevenção aos agravos decorrentes.

Considerando o papel epidemiológico dos cães e a possibilidade de veicular antropozoonoses, em especial a raiva, emerge a necessidade de elaborar e implementar medidas de bem-estar animal, de monitoramento e de prevenção de acidentes.

\section{AGRADECIMENTOS}

À Fundação de Amparo a Pesquisa e Inovação do Estado de Santa Catarina (FAPESC), Chamada Pública FAPESC № 10/2015 - PPSUS.

\section{REFERÊNCIAS}

BUSATTO, V. M.; MORIWAKI, A. M.; MARTINS, D. A. C. HORÁCIO, P. M.; UCHIMURA, N. S.; UCHIMURA, T. T. Perfil do tratamento profilático antirrábico humano no sul do Brasil. Ciência Cuidado e Saúde, v. 13, n. 4, p. 617-624, 2014.

BUSO, D. S.; NUNES, C. M.; QUEIROZ, L. H. Características relatadas sobre animais agressores submetidos ao diagnóstico de raiva, São Paulo, Brasil, 1993-2007. Cadernos Saúde Pública, Rio de Janeiro, v. 25, n.12, p. 2747-2751, 2009.

BRASIL. Unidade Técnica de Zoonoses (UT Zoonoses) - Mapas da Raiva no Brasil. Brasilia: Ministério da Saúde. Secretaria de Vigilância em Saúde (SVS) Departamento de Vigilância das Doenças Transmissíveis (DEVIT). Coordenação Geral de Doenças Transmissíveis (CGDT), 2016. 13 p.

CAVALCANTE, K. K.; FLORÊNCIO, C. M.; ALENCAR, C. H. Profilaxia antirrábica humana pós-exposição: características dos atendimentos no estado de Ceará, 2007-2015. Journal Health Biology and Science, v. 5, n. 4, p. 337-345, 2017. 
DEL CIAMPO, L. A.; RICCOA, R. G.; ALMEIDA, C. A. BONILHA, L. R. de C. M.; SANTOS, T. C. C. Acidentes de mordeduras de cães na infância. Revista Saúde Pública, v. 34, n. 4, p. 411-412, 2000.

FERRAZ, L.; BUSATO, M. A.; FERRAZZO, J. F.; RECH, A. P.; SILVA, P. S. da. Notificações dos atendimentos antirrábico humano: perfil das vítimas e dos acidentes. HYGEIA: Revista Brasileira de Geografia Médica e da Saúde, v. 9, n.16, p.182 - 189 , 2013.

FRIAS, D. F. R.; LAGES, S. L.; CARVALHO, A. A. B. Avaliação da conduta de profilaxia antirrábica indicada para pessoas envolvidas em agravos com cães e gatos no município de Jaboticabal, SP, no período de 2000 a 2006. Revista Brasileira de Epidemiologia, v. 14, n. 4, p. 722-32, 2011.

FRIAS, D. F. R.; CARVALHO, A. A. B.; NUNES, J. O. R. Proposta de nova metodologia de apoio para indicação racional de profilaxia antirrábica. Arquivos de Ciências da Saúde UNIPAR, v. 20, n. 1, p. 9-18, 2016.

GOMES, A. P.; ESPERIDIÃO-ANTONIO, V.; MENDONÇA, B. G.; BENEDITO, H. P. L.; VITORINO, R. R.; PRADO, M. R. M. C.; PRADO JUNIOR, P. P.; HENRIQUES, B. D.; SANTANA, L. A. Raiva Humana. Revista Brasileira de Clínica Médica, v. 10, n. 4, p. 334-40, 2012.

HADDAD JUNIOR, V.; CAMPOS NETO, M. F.; MENDES, A. L. Mordeduras de animais (selvagens e domésticos) e humanas. Revista de Patologia Tropical, v. 42, n. 1, p. 1319, 2013.

LIMA, E. C. F.; FARIA, M. D.; MORAIS, R. M. R. B. L.; OLIVEIRA, L. M. S. R.; LIMA, E. H. F.; COSTA, C. S. Interações entre meio ambiente, atendimentos antirrábicos e acidentes por animais peçonhentos no município de Petrolina (PE). Saúde Meio Ambiente, v. 6, n. 1, p. 54-70, 2017.

IBGE. Instituto Brasileiro de Geografia e Estatística. Ministério do Planejamento, Orçamento e Gestão. Cidades. Disponível em http://cidades.ibge.gov.br/v3/cidades/home-cidades. Acesso 20 de dez. 2017.

LOPES, J. T. S.; SILVA, S. B.; MOTA, D.; VALENTE, S. F.; VILGES, K. M. A.; OLIVEIRA, S. V.; ARAÚJO, W. N.; PINTO JUNIOR, V. L. Análise dos acidentes por animais com potencial de transmissão para raiva no município de Caçapava do Sul, Estado do Rio Grande do Sul, Brasil. Revista Medicina e Saúde de Brasília, v. 3, n. 3, p. 210-23, 2014.

MOUTINHO, F. F. B.; NASCIMENTO, E. R.; PAIXÃO, R. L. Raiva no Estado do Rio de Janeiro, Brasil: análise das ações de vigilância e controle no âmbito municipal. Ciência \& Saúde Coletiva, v. 20, n. 2, p. 577-586, 2015.

OLIVEIRA, V. M. R.; PEREIRA, P. L. L.; SILVA, J. A.; MIRANDA, C. F. J.; RODRIGUES, K. O.; RODRIGUES, T. O.; MOREIRA, E. C. Mordedura canina e atendimento antirrábico humano em Minas Gerais. Arquivo Brasileiro de Medicina Veterinária e Zootecnia, v. 64, n. 4, p. 891-898, 2012.

PARANHOS, N. T.; SILVA, E. A.; BERNARDI, F.; MENDES, M. C. N. C.; JUNQUEIRA, D. M. A. G.; SOUZA, I. O. M.; ALBUQUERQUE, J. O. M.; ALVES, J. C. M.; MACHADO, M. 
N. P. Estudo das agressões por cães, segundo tipo de interação entre cão e vítima, e das circunstâncias motivadoras dos acidentes, município de São Paulo, 2008 a 2009. Arquivo Brasileiro de Medicina Veterinária e Zootecnia, v. 65, n. 4, p. 1033-1040, 2013.

PEREIRA, J.; BOSCHETTI, M. A.; PEREIRA, J. Estratégias de gestão para melhoria no atendimento antirrábico humano em Florianópolis. In: PEREIRA, M. F.; COSTA, A. M.; MORITZ, G. O.; BUNN, D. A. (org). Contribuições para a Gestão do SUS. Gestão da Saúde Pública. Florianópolis: Fundação Boiteux, v. 10, 2016.

QUEIROZ, L. H.; BUSO, D. S.; SILVA, J. E. Aspectos epidemiológicos das agressões por cães sob o ponto de vista do cão agressor e das vítimas. Veterinária e Zootecnia, v. 20, n. 3, p. 296-306, 2013.

SANTOS, C. V. B.; MELO, R. B.; BRANDESPIM, D. F.. Perfil dos atendimentos antirrábicos humanos no agreste pernambucano, 2010-2012. Epidemiologia e Serviços de Saúde, v. 26, n. 1, p.161-168, 2017.

SILVA, G. M.; BRANDESPIM, D. F.; ROCHA, M. D. G.; LEITE, R. M. B.; OLIVEIRA, J. M. B. Notificações de atendimento antirrábico humano na população do município de Garanhuns, Estado de Pernambuco, Brasil, no período de 2007 a 2010. Epidemiologia e Serviços de Saúde, v. 22, n. 1, p. 95-102, 2013.

SILVA, C. J.; BELO, M. A. A. Censo canino e felino: sua importância no controle de zoonoses na cidade de Cacoal - RO. Enciclopédia Biosfera, v. 11 n. 21, p. 3368-3373, 2015.

SILVA, A. F.; COSTA, E. C. Acidentes rábicos: Um olhar sobre os fatores desencadeantes e seu mapeamento territorial em um município do Estado do Ceará. In: PEREIRA, M. F.; COSTA, A. M.; MORITZ, G. O.; BUNN, D. A. (org). Contribuições para a Gestão do SUS. Gestão da Saúde Pública. Florianópolis: Fundação Boiteux, v. 10, 2016.

VELOSO, R. D.; AERTS, D. R. G. C.; FETZER, L. O.; ANJOS, C. B.; SANGIOVANNI, J. C. Motivos de abandono do tratamento antirrábico humano pós-exposição em Porto Alegre (RS, Brasil). Ciência \& Saúde Coletiva, v. 16, n. 2, p.537-546, 2011. 